\title{
CD133, a Progenitor Cell Marker, is Reduced in Nasal Polyposis and Showed Significant Correlations with TGF- $\beta 1$ and IL-8
}

\author{
Wagner Vargas Souza Lino ${ }^{1, *}$ André Luis Lacerda Bachi ${ }^{1,2,4, *}$ José Arruda Mendes Neto ${ }^{1}$ \\ Gabriel Caetani ${ }^{3}$ Jônatas Bussador do Amaral ${ }^{10}$ Rogério Pezato ${ }^{1,3}$
}

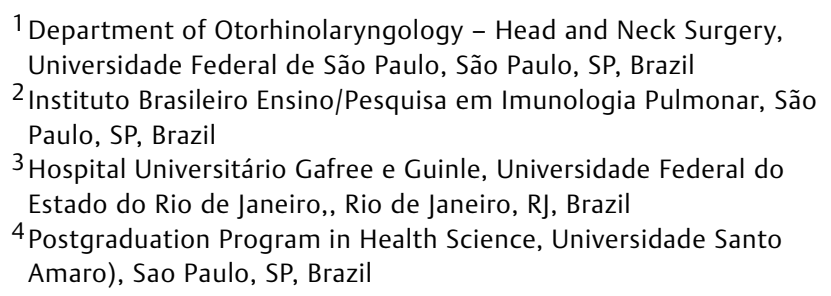

Address for correspondence Jônatas Bussador do Amaral, PhD, ORL Lab, Departamento de Otorrinolaringologia e Cirurgia de Cabeça e Pescoço, Universidade Federal de São Paulo, Rua Pedro de Toledo, $781,1^{\circ}$ andar, sala 3, Vila Clementino, São Paulo, SP, 04039-032, Brazil (e-mail: jbamaral@unifesp.br).

Int Arch Otorhinolaryngol 2022;26(1):e91-e96.

\begin{abstract}
Keywords

- nose diseases

- nasal polyps

- aspirin-induced asthma

- AC133 antigen

- transforming growth factor $\beta 1$

- interleukin-8

Introduction Combination of chronic inflammation and an altered tissue remodeling process are involved in the development of Chronic Rhinosinusitis with Nasal Polyps (CRSwNP). Studies demonstrated that mesenchymal stem cells expressing the progenitor gene CD133 were involved in a significant reduction of the chronic inflammatory process in the polypoid tissue.

Objective To evaluate the levels of CD133 (Prominin-1) in nasal polypoid tissue and its correlation with interleukin-8 (IL-8) and transforming growth factor $\beta 1$ (TGF- $\beta 1$ ).

Methods A total of 74 subjects were divided in the following groups: control group $(n=35)$; chronic rhinosinusitis with nasal polyps nonpresenting comorbid asthma and aspirin intolerance (CRSwNPnonAl) group $(n=27)$; and chronic rhinosinusitis with nasal polyps presenting comorbid asthma and aspirin intolerance (CRSWNPAI) group $(n=12)$. Histologic analysis and also evaluation of the concentration of CD133, IL-8, and TGF- $\beta 1$ by enzyme-linked immunosorbent assay (ELISA) kits were performed in nasal tissue obtained from nasal polypectomy or from middle turbinate tissue.

Results Higher eosinophilic infiltration was found in both CRSwNP groups by histologic analysis. Lower levels of TGF- $\beta 1$ and IL-8 were observed in both CRSwNP groups when compared with the control group, whereas the CD133 levels were significantly reduced only in the CRSwNPnonAl group compared with the control group.

Conclusion It was demonstrated that the nasal mucosa presenting polyposis showed a significant reduction of CD133 levels, and also that this reduction was significantly correlated with the reduction of TGF- $\beta 1$ levels, but not with IL-8 levels. Therefore, these findings may be involved in the altered inflammatory and remodeling processes observed in the nasal polyposis.
\end{abstract}

These authors contributed equally to the present work.

received

April 26, 2020

accepted

November 30, 2020

published online

July 25, 2021
DOI https://doi.org/ 10.1055/s-0041-1726043. ISSN 1809-9777.

\footnotetext{
(C) 2021. Fundação Otorrinolaringologia. All rights reserved. This is an open access article published by Thieme under the terms of the Creative Commons Attribution-NonDerivative-NonCommercial-License, permitting copying and reproduction so long as the original work is given appropriate credit. Contents may not be used for commercial purposes, or adapted, remixed, transformed or built upon. (https://creativecommons.org/ licenses/by-nc-nd/4.0/)

Thieme Revinter Publicações Ltda., Rua do Matoso 170, Rio de Janeiro, RJ, CEP 20270-135, Brazil
} 


\section{Introduction}

Chronic rhinosinusitis with nasal polyps (CRSwNP) is a complex illness that affects many people worldwide. ${ }^{1,2}$ It can be subdivided into eosinophilic and noneosinophilic chronic rhinosinusitis, ${ }^{3}$ being the presence of eusinophilic infiltrate frequently associated with poorer surgical outcome after surgery and with more severe symptoms. ${ }^{4,5}$ It has been reported that CRSwNP is a result of anomalous growth of the nasal mucosa, caused by the combination of chronic inflammation and an altered tissue remodeling process that lead to mechanical dysfunction. ${ }^{6-8}$ Histological studies have shown that nasal polyps are characterized by the generation of the altered extracellular matrix, tissue infiltration by inflammatory cells, presence of pseudocysts, and edema. ${ }^{9,10}$

Although CRSwNP is a complex illness, some aspects such as low drug responses, local aggressiveness, and high rate of recurrence after surgery are observed in an overwhelming majority of patients with this disease. ${ }^{11}$ In addition, there is a specific endotype of patients with CRSwNP, named as aspirin-exacerbated respiratory disease (AERD), which presents not only severe asthma and recurrent nasal polyposis, as well as an exacerbated airway response following ingestion of aspirin or other nonsteroidal anti-inflammatory drugs (NSAIDs) that inhibit cyclooxygenase-1 (COX-1) ${ }^{1,11}$

In terms of clinical treatment modalities, in a general way, the treatment aims to promote the reduction of the chronic inflammatory process by the use of anti-inflammatory and immunomodulatory agents. ${ }^{6}$ However, new therapeutic modalities that act directly on mechanical dysfunction have been suggested, mainly trying to increase interstitial hydrostatic pressure. ${ }^{12,13}$

By the way, studies reported that the presence of mesenchymal stem cells in the polypoid tissue was associated with a decreased number of inflammatory cells and proinflammatory interleukins, as well as increased regulatory T-cells and interleukin-10 (IL-10), which consequently led to the reduction of the chronic inflammatory process. ${ }^{14,15}$ In addition, it was demonstrated that nasal polyp-derived mesenchymal stem cells presented decreased expression of immunoassociated molecules, but presented overexpression of progenitor genes when compared with bone marrowderived mesenchymal stem cells, ${ }^{16}$ which may be associated with the altered remodeling process. Among the gene overexpressed by the nasal polyp-derived mesenchymal stem cells was the $C D 133$ (prominin- 1 ), ${ }^{16}$ a pentaspan membrane glycoprotein 1 , widely expressed by the progenitor cells. ${ }^{17,18}$

Beyond a well-known stem cell marker, studies have demonstrated that CD133 is involved in cell growth and self-renewal, tissue repair, regeneration, remodeling, resistance, metabolism, differentiation, autophagy, and apoptosis, especially, in terms of tumor tissue. ${ }^{19-23}$ Other studies evaluated the role of bone marrow-derived CD133+ stem cells in the regeneration of ischemic heart tissue, ${ }^{24,25}$ and in endstage liver disease, ${ }^{26}$ with promising results. Furthermore, the presence of CD133+ bone marrow-derived stem/progenitor cells was associated with increased levels of cytokines associated with Th1 immunological profile. ${ }^{26,27}$
Based on these pieces of information, studies aiming to evaluate the presence of CD133 in nasal polypoid tissue from individuals with chronic rhinosinusitis clearly could amplify the knowledge of the mechanisms involved in the development of nasal polyposis. Therefore, in the present study, we aimed to evaluate the levels of CD133 in nasal polypoid tissue from individuals with chronic rhinosinusitis compared with healthy nasal tissue, as well as its correlation with two well-known cytokines involved in CRSwNP, such as IL-8 and also TGF- $\beta 1$.

\section{Methods}

\section{Study Subjects}

A total of 74 subjects (mean age: $52.3 \pm 12.7$ years old) were enrolled in the present study. All volunteers were recruited from a primary health care program belonging to the Department of Otorhinolaryngology and Head and Neck Surgery of the Federal University of Sao Paulo. The participants were separated in two groups: control group, composed by healthy subjects; and chronic rhinosinusitis with nasal polyps (CRSwNP), diagnosed in accordance with the 2020 European position paper on Rhinosinusitis and Nasal Polyps (EPOS 2020). ${ }^{2}$ It is worth to highlight that 12 patients in the CRSwNP group presented comorbid asthma and aspirin intolerance (diagnosed through medical history). Therefore, the volunteers of the CRSwNP group were separated into two subgroups: without aspirin intolerance (CRSwNPnonAI) and with aspirin intolerance (CRSwNPAI) ( - Table 1).

All the procedures and laboratory experiments agreed with Ethical Standards and also with the Declaration of Helsinki. ${ }^{28}$ All the volunteers signed the informed consent previously approved by the Research and Ethic Committee of the Federal University of Sao Paulo (number 79787817.3.0000.5505).

\section{Nasal Tissue Samples}

Nasal tissue samples from the CRSwNP group were obtained by nasal polypectomy, and from the control group by septoplasty and turbinoplasty of patients with nasal obstruction due to septal deviation and pneumatized middle turbinate (concha bullosa), respectively.

All nasal tissue samples were resected under strict aseptic technique during surgery at Federal University of Sao Paulo. Freshly obtained nasal tissues were weighed and divided in 2 portions: one was fixed using $10 \%$ acetaldehyde and was maintained for 24 hours at room temperature; the other

Table 1 Demographics of the study population

\begin{tabular}{|l|l|l|l|}
\hline & Control & CRSwNPNonAI & CRSwNPAI \\
\hline Patients (n) & 35 & 27 & 12 \\
\hline Male, $\mathrm{n}(\%)$ & $15(42.85)$ & $6(22.22)$ & $9(75)$ \\
\hline $\begin{array}{l}\text { Aspirin } \\
\text { intolerance, } \\
\mathrm{n}(\%)\end{array}$ & $0(0)$ & $0(0)$ & $12(100)$ \\
\hline
\end{tabular}

Abbreviations: CRSwNPNonAl, chronic rhinosinusitis with nasal polyps without aspirin intolerance; CRSwNPAI, chronic rhinosinusitis with nasal polyps with aspirin intolerance. 
portion was mixed with lysis buffer (PBS $+0.2 \%$ Tween-20) containing protease inhibitor (Merck, Darmstadt, Germany) at a ratio of $3 \mu \mathrm{L}$ buffer $/ \mu$ g of nasal tissue and stored at $-80^{\circ} \mathrm{C}$.

\section{Nasal Tissue Homogenate}

All nasal tissue portions mixed with lysis buffer were mechanically submitted to homogenization (Tissue Ruptor, QIAGEN, USA) at a speed of $10,000 \mathrm{rpm}$ until complete dissociation. After that, the samples were placed on ice for 30 minutes and were centrifuged at $10,000 \mathrm{~g}$ and $4^{\circ} \mathrm{C}$ for 10 minutes. The supernatant was collected, aliquoted, and stored at $-80^{\circ} \mathrm{C}$.

\section{Nasal Tissue Histology}

The nasal tissue portions previously fixed were embedded in paraffin, and 4- $\mu \mathrm{m}$-thick sections were obtained using a microtome. All sections were affixed onto Superfrost Plus glass slides (Menzel Glaser, Braunschweig, Germany) and were dried at $60^{\circ} \mathrm{C}$ for a few hours. For deparaffinization, the slides were washed successively in xylene (3 times for 10 minutes), $100 \%$ ethanol ( 2 times for 5 minutes), $90 \%$ ethanol ( 2 times for 5 minutes), and $70 \%$ ethanol ( 2 times for 5 minutes). The nuclei were stained with alum hematoxylin (Lillie-Mayer solution) for 5 minutes and rinsed in running tap water. Differentiation was performed with $0.3 \%$ acid alcohol, and sections were rinsed again in running tap water and, subsequently, in Scott tap water substitute (sodium hydrogen carbonate $10 \mathrm{~g}$, magnesium sulfate $100 \mathrm{~g}$, distilled water $5 \mathrm{~L}$ ).

After being rinsed in tap water, the sections were stained with eosin solution ( $1 \%$ eosin Y $400 \mathrm{~mL}, 1 \%$ aqueous phloxine $40 \mathrm{~mL}, 95 \%$ alcohol $3100 \mathrm{~mL}$, and glacial acetic acid $16 \mathrm{~mL}$ ) for 2 minutes, then they were dehydrated and cleared.

Histological examination was performed by a pathologist through a Leica DM2000 binocular microscope at 400x magnification. The absolute number of eosinophils per high-power field (HPF) was counted in an average of 10 fields of view selected from the most inflamed area of tissue.

\section{Determination of Cytokines and CD133 in Nasal Tissue Homogenate}

Cytokine concentrations of IL-8 and TGF- $\beta 1$ (R\&D Systems, Minneapolis, Minnesota, USA), and of CD133 (Elabscience, Houston, Texas, USA) protein were determined in nasal tissue homogenate by ELISA commercial kit following the guidelines of the manufacturer. Cytokines and CD133 concentrations were normalized by the total content of protein, determined by the Bradford method ${ }^{29}$.

\section{Statistical Analysis}

The analyses were performed using PASW Statistics for Windows, version 18.0 (SPSS Inc., Chicago, IL, USA), and the significance level was set at $p<0.05$. The KolmogorovSmirnov test and also the Levene test were used to assess the normality of distribution. As the data showed a non-normal distribution, the Kruskal-Wallis test was used to evaluate the occurrence of statistically significant differences between the volunteer groups.

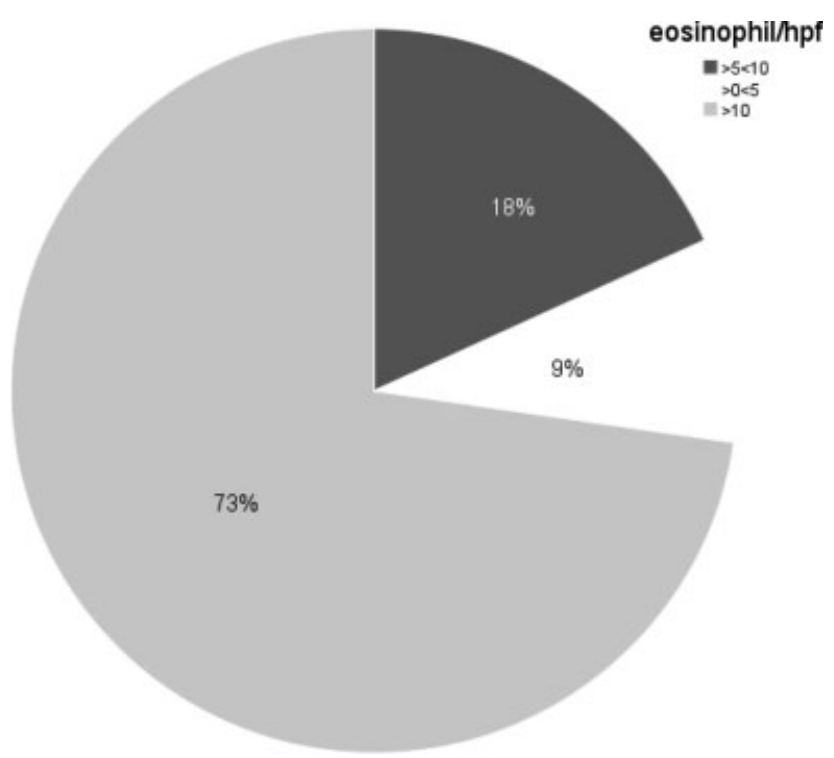

Fig. 1 Eosinophil count per high-power field in the nasal polyposis (all cases) group.

\section{Result}

\section{Eosinophil Infiltration on Nasal Tissue}

As shown in - Fig. 1, none of the volunteers in the control group showed eosinophil infiltration in the nasal tissue, whereas $73 \%$ of the volunteers in the CRSwNP group showed $>10$ eosinophils per HPF, $18 \%$ showed 5 to 10 eosinophils per $\mathrm{HPF}$, and $9 \%$ showed $<5$ eosinophils per HPF.

\section{Levels of CD133, TGF- $\beta 1$ and IL-8 in Nasal Tissue Homogenates}

-Fig. 2 shows higher levels of CD133 (-Fig. 2A) in the nasal tissue homogenates from the control group than in the CRSwNPnonAI group $(p=0.023)$. In relation to TGF- $\beta 1$ levels

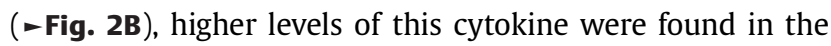
control group when compared with the values observed in the CRSwNPnonAI group $(p=0.017)$ and in the CRSwNPAI group $(p=0.04)$. Similarly, as with CD133 and TFG- $\beta 1$, the IL-8 levels (-Fig. 2C) were significantly higher in the control group when compared with the values found in the CRSwNPnonAI $(p<0.001)$ and in the CRSwNPAI $(p<0.001)$ groups.

\section{Correlations between the Levels of CD133 and TGF- $\beta 1$ or IL-8 in Nasal Tissue Homogenates}

As shown in -Table 2, significant positive correlations between CD133 and TGF- $\beta 1$ were found in all volunteer groups. In relation to the correlation between CD133 and IL-8, we found a positive correlation between these molecules only in the control group (-Table 2 ).

\section{Discussion}

The results obtained in the present study showed for the first time that nasal tissue presenting chronic rhinosinusitis with nasal polyposis but without asthma and aspirin intolerance, demonstrates a significant reduction of the levels of CD133, TGF- $\beta 1$ and IL-8 when compared with healthy nasal tissue 
A CD133

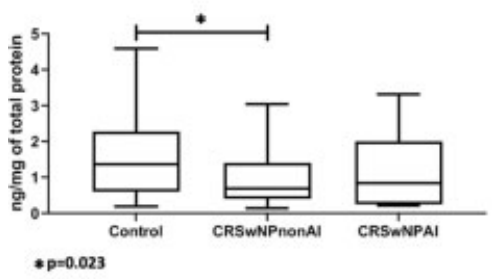

B TGF- $\beta 1$

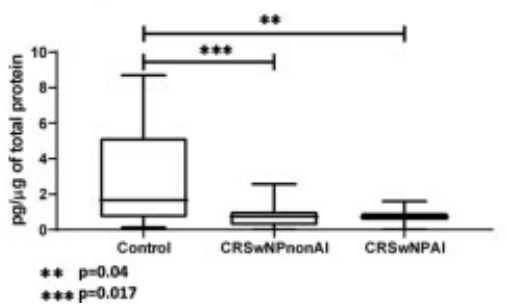

C IL-8

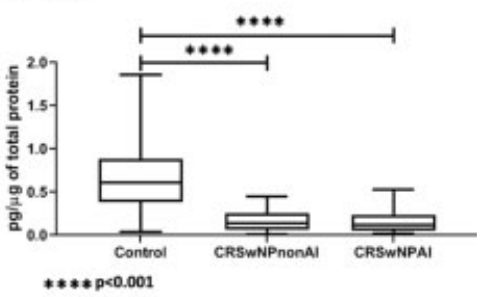

Fig. 2 Levels of cytokines in nasal tissue homogenates. Abbreviations: CRSwNPNonAI, chronic rhinosinusitis with nasal polyps without aspirin intolerance; CRSwNPAI, chronic rhinosinusitis with nasal polyps with aspirin intolerance.

Table 2 Correlations between the levels of CD133 and TGF- $\beta 1$ or IL-8 in nasal tissue homogenates

\begin{tabular}{|l|l|l|l|l|l|l|}
\hline Groups & \multicolumn{2}{|l|}{ Control $(\boldsymbol{n}=35)$} & \multicolumn{2}{l|}{ CRSwNnonPAI $(\boldsymbol{n}=27)$} & $\begin{array}{l}\text { CRSwNPAI } \\
(\boldsymbol{n}=12)\end{array}$ \\
\hline Variables & TGF- $\beta 1$ & $\mathrm{IL}-8$ & $\mathrm{TGF}-\beta 1$ & $\mathrm{IL}-8$ & TGF- $\beta 1$ & $\mathrm{IL}-8$ \\
\hline CD133 & $\begin{array}{l}\mathrm{r}=0.466 ; \\
p=0.04\end{array}$ & $\begin{array}{l}\mathrm{r}=0.725 ; \\
p<0.0001\end{array}$ & $\begin{array}{l}\mathrm{r}=0.909 ; \\
<0.0001\end{array}$ & $\begin{array}{l}\mathrm{r}=0.403 ; \\
p=0.063\end{array}$ & $\mathrm{r}=0.905 ; p<0.0001$ & $\mathrm{r}=0.274 ; p=0.229$ \\
\hline
\end{tabular}

Abbreviations: CRSwNPAI, chronic rhinosinusitis with nasal polyps with aspirin intolerance; CRSwNnonPAl, chronic rhinosinusitis without nasal polyps with aspirin intolerance; IL-8, interleukin-8; TGF- $\beta 1$, transforming growth factor $\beta 1$.

(control group). Interestingly, the CRSwNPAI group showed reduced levels of TGF- $\beta 1$ and IL- 8 compared with the control group, whereas the CD133 levels did not show a significant difference when compared with the other volunteer groups. Concerning the correlation analysis, significant positive correlations were found between the levels of CD133 and TGF$\beta 1$ or IL-8 in the control group, whereas the groups presenting chronic rhinosinusitis with nasal polyposis showed only a positive correlation between CD133 and TGF- $\beta 1$.

According to the literature, the expression of CD133 by stem cells has been involved in tissue regeneration, repair, and growth, ${ }^{24,25}$ as well as in immunosuppressive situations and environments, such as in tumor microenvironments. ${ }^{30}$ Based on these properties, the role of $C D 133$ in the pathogenesis of chronic inflammatory diseases, especially when an altered tissue remodeling represents an essential characteristic for its development, such as in the nasal polyposis, ${ }^{6-8}$ needs to be evaluated.

In this respect, our group previously demonstrated that CD133 expression in polyp-derived mesenchymal stem cells was higher than in bone marrow-derived mesenchymal stem cells. ${ }^{16}$ However, as mentioned above, in the present study, a lower CD133 level was found in the homogenate from the nasal tissue of the CRSwNPnonAI group in comparison with the values observed in the control group. Despite the apparently opposite results, it is worth mentioning that, in the previous study, ${ }^{16}$ the analysis of $C D 133$ expression was performed in one isolated cell-type from nasal polyposis and not in the nasal tissue presenting or not polyposis. Here, instead of analyzing CD133 expression, we aimed to measure the concentration of the CD133 protein in nasal tissue to evaluate its role in nasal polyposis.

The observation that the CRSwNPnonAI showed reduced CD133 levels can lead us to suggest that the chronic inflammatory response associated with polyposis acts by inhibiting
CD133 production, in order to maintain an inflamed microenvironment. In addition, the similar CD133 levels found in the control group and in the CRSwNPAI group can reinforce our suggestion described above, since that, in the polyposis group, the therapy based on the use of intranasal corticosteroids, which is considered the first-line therapy, not only can act to minimize the local inflammatory response but also

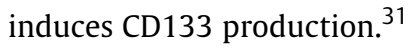

Regarding the induction of $C D 133$ expression, it has been shown that TGF- $\beta 1$, a pivotal molecule involved both in the remodeling and immunoregulation process, can regulate CD133 expression through the demethylation of the CD133 gene promoter $\mathrm{P} 1{ }^{19}$ In addition, it was also reported that CD133 + cells could also increase TGF- $\beta 1$ activity via integrin molecules. ${ }^{32}$ Thus, CD133 and TGF- $\beta 1$ are closely associated. Corroborating these pieces of information, and also in agreement with the literature, ${ }^{8}$ we observed a significant reduction of TGF- $\beta 1$ levels in nasal tissue homogenates from both volunteer groups with nasal polyposis. In addition, our results of a positive correlation between these molecules observed in the three volunteer groups can putatively reinforce the proposal that these molecules act together in many situations and sites, including in the nasal tissue.

It is widely accepted that TGF- $\beta 1$ plays a relevant role in Tcell maturation and differentiation, depending on the cytokines present in the inflammatory milieu. ${ }^{33-35}$ For instance, the presence of TGF- $\beta 1$ and IL- 2 prompts differentiation into Treg cells; ${ }^{35}$ with interleukin-4 (IL-4) there is differentiation into Th9 cells; ${ }^{33}$ and its association with interleukin-6 (IL-6) and interleukin-21 (IL-21) leads to the differentiation into Th17 cells. ${ }^{36}$ Furthermore, it is well-known that TGF- $\beta 1$ is capable of inhibiting both Th1 and Th2 cell differentiation.

In relation to CRSwNP, depending on the inflammatory pathophysiology, three different endotypes have been reported: (1) Th1 profile, which, in general, is associated 
with predominant neutrophil infiltration and increased levels of IL-2, interferon (IFN), and tumor necrosis factor-a (TNF-a); (2) Th2 profile, which is mainly characterized by increased eosinophil infiltration and higher levels of IL-4, interleukin-5 (IL-5), IL-10, interleukin-13 (IL-13), and immunoglobulin E (IgE); and (3) Th17 profile, which is associated with increased expression of IL-6, interleukin 17 I(L-17), interleukin-22 (IL-22), and TNF- $\alpha{ }^{37}$

Based on these pieces of information, the prominent nasal tissue eosinophil infiltration found in the CRSwNP groups (91\%) allows us to suggest that a Th2 profile was predominant in these groups. Therefore, the reduced levels of TGF- $\beta 1$ and of other cytokines related to other Th-cell phenotypes, such as interleukin-8 (IL-8) and interleukin 12 (IL-12), which are related to the Th- 1 profile, in these volunteer groups, were an expected finding.

In relation to IL-8, a proinflammatory cytokine, it is widely accepted that it acts as a chemoattractant molecule, especially for neutrophils. ${ }^{38,39}$ It has been reported that this cytokine can be locally produced by nasal fibroblasts 40 and, as described above, depending on the context, may be involved in the neutrophil infiltration found in Th-1 phenotype-derived nasal polyposis. Therefore, the reduced IL-8 levels found in the nasal tissue homogenate from both CRSwNP groups corroborate our data that a Th-2 phenotype was predominant in these groups. Beyond its chemoattractant action, IL-8 also is involved in the angiogenesis process. $^{39}$ By the way, it has been reported that CD133 can induce IL-8 expression, leading to increased angiogenesis. ${ }^{27,41}$ This data can support our observation of a positive correlation between CD133 levels and IL-8 found in the control group. Interestingly, both CRSwNP groups with nasal polyposis did not show the same correlation, showing that polyposis development disturbs the close relationship between these molecules.

\section{Conclusion}

In conclusion, in the present study, we were able to demonstrate, for the first time, that nasal mucosa presenting polyposis has a significant reduction of CD133 levels, and also that this reduction was significantly correlated with the reduction of TGF- $\beta 1$ levels, but not with the reduction of IL-8 levels. These findings, in association with the presence of the Th-2 phenotype, reinforce the knowledge that the development of CRSwNP may affect the nasal tissue cytokine pattern, and now CD133 levels, which consequently can putatively influence in both inflammatory and remodeling processes observed in nasal polyposis.

Conflict of Interests

The authors have no conflict of interests to declare.

\section{References}

1 Hulse KE, Stevens WW, Tan BK, Schleimer RP. Pathogenesis of nasal polyposis. Clin Exp Allergy 2015;45(02):328-346. Doi: $10.1111 /$ cea. 12472
2 Fokkens WJ, Lund VJ, Hopkins C, et al. European Position Paper on Rhinosinusitis and Nasal Polyps 2020. Rhinology 2020;58(Suppl S29):1-464. Doi: 10.4193/Rhin20.600

3 Nakayama T, Sugimoto N, Okada N, et al. JESREC score and mucosal eosinophilia can predict endotypes of chronic rhinosinusitis with nasal polyps. Auris Nasus Larynx 2019;46(03): 374-383. Doi: 10.1016/j.anl.2018.09.004

4 Cho S-W, Kim DW, Kim J-W, Lee CH, Rhee CS. Classification of chronic rhinosinusitis according to a nasal polyp and tissue eosinophilia: limitation of current classification system for Asian population. Asia Pac Allergy 2017;7(03):121-130

5 Tokunaga T, Sakashita M, Haruna T, et al. Novel scoring system and algorithm for classifying chronic rhinosinusitis: the JESREC Study. Allergy 2015;70(08):995-1003. Doi: 10.1111/all.12644

6 Fokkens WJ, Lund VJ, Mullol J, et al. EPOS 2012: European position paper on rhinosinusitis and nasal polyps 2012. A summary for otorhinolaryngologists. Rhinology 2012;50(01):1-12

7 Pezato R, Voegels RL, Pinto Bezerra TF, Perez-Novo C, Stamm AC, Gregorio LC. Mechanical disfunction in the mucosal oedema formation of patients with nasal polyps. Rhinology 2014;52 (02):162-166. Doi: 10.4193/Rhin 13.066

8 Pezato R, Balsalobre L, Lima M, et al. Convergence of two major pathophysiologic mechanisms in nasal polyposis: immune response to Staphylococcus aureus and airway remodeling. J Otolaryngol Head Neck Surg 2013;42:27-27. Doi: 10.1186/19160216-42-27

9 Stevens WW, Lee RJ, Schleimer RP, Cohen NA. Chronic rhinosinusitis pathogenesis. J Allergy Clin Immunol 2015;136(06): 1442-1453. Doi: 10.1016/j.jaci.2015.10.009

10 DeConde AS, Mace JC, Levy JM, Rudmik L, Alt JA, Smith TL. Prevalence of polyp recurrence after endoscopic sinus surgery for chronic rhinosinusitis with nasal polyposis. Laryngoscope 2017;127(03):550-555. Doi: 10.1002/lary.26391

11 Brescia G, Zanotti C, Parrino D, Barion U, Marioni G. Nasal polyposis pathophysiology: Endotype and phenotype open issues. Am J Otolaryngol 2018;39(04):441-444. Doi: 10.1016/j. amjoto.2018.03.020

12 Gregório L, Pezato R, Felici RS, Kosugi EM. Fibrotic Tissue and Middle Turbinate Exhibit Similar Mechanical Properties. Is Fibrosis a Solution in Nasal Polyposis? Int Arch Otorhinolaryngol 2017; 21(02):122-125. Doi: 10.1055/s-0036-1593728

13 Balsalobre L, Pezato R, Mangussi-Gomes J, et al. What is the Impact of Positive Airway Pressure in Nasal Polyposis? An Experimental Study. Int Arch Otorhinolaryngol 2019;23(02):147-151. Doi: 10.1055/s-0038-1676095

14 Pezato R, de Almeida DC, Bezerra TF, et al. Immunoregulatory effects of bone marrow-derived mesenchymal stem cells in the nasal polyp microenvironment. Mediators Inflamm 2014; 2014:583409. Doi: 10.1155/2014/583409

15 Pezato R, Gregorio L, Voegels R, et al. Hypotheses about the Potential Role of Mesenchymal Stem Cell on Nasal Polyposis: A Soft Inflamed Tissue Suffering from Mechanical Dysfunction. Austin Immunology 2016:1

16 de Oliveira PWB, Pezato R, Agudelo JSH, et al. Nasal PolypDerived Mesenchymal Stromal Cells Exhibit Lack of ImmuneAssociated Molecules and High Levels of Stem/Progenitor Cells Markers. Front Immunol 2017;8:39. Doi: 10.3389/ fimmu.2017.00039

17 Miraglia S, Godfrey W, Yin AH, et al. A novel five-transmembrane hematopoietic stem cell antigen: isolation, characterization, and molecular cloning. Blood 1997;90(12):5013-5021. Doi: 10.1182/ blood.V90.12.5013

18 Li Z. CD133: a stem cell biomarker and beyond. Exp Hematol Oncol 2013;2(01):17-17. Doi: 10.1186/2162-3619-2-17

19 You H, Ding W, Rountree CB. Epigenetic regulation of cancer stem cell marker CD133 by transforming growth factor- $\beta$. Hepatology 2010;51(05):1635-1644. Doi: 10.1002/hep.23544 
20 Takenobu H, Shimozato O, Nakamura T, et al. CD133 suppresses neuroblastoma cell differentiation via signal pathway modification. Oncogene 2011;30(01):97-105. Doi: 10.1038/onc.2010.383

21 Beier D, Hau P, Proescholdt M, et al. CD133(+) and CD133(-) glioblastoma-derived cancer stem cells show differential growth characteristics and molecular profiles. Cancer Res 2007;67(09): 4010-4015. Doi: 10.1158/0008-5472.can-06-4180

22 Nadal R, Ortega FG, Salido M, et al. CD133 expression in circulating tumor cells from breast cancer patients: potential role in resistance to chemotherapy. Int J Cancer 2013;133(10):2398-2407. Doi: $10.1002 /$ ijc.28263

23 Koennecke M, Böscke R, Pfannerstill A-C, et al. Neuronal Differentiation Capability of Nasal Polyps of Chronic Rhinosinusitis. Arch Immunol Ther Exp (Warsz) 2017;65(05):431-443. Doi: 10.1007/s00005-017-0456-8

24 Ma N, Ladilov Y, Moebius JM, et al. Intramyocardial delivery of human CD133 + cells in a SCID mouse cryoinjury model: Bone marrow vs. cord blood-derived cells. Cardiovasc Res 2006;71(01): 158-169. Doi: 10.1016/j.cardiores.2006.03.020

25 Colombo A, Castellani M, Piccaluga E, et al. Myocardial blood flow and infarct size after CD133+ cell injection in large myocardial infarction with good recanalization and poor reperfusion: results from a randomized controlled trial.J Cardiovasc Med (Hagerstown) 2011;12(04):239-248. Doi: 10.2459/JCM.0b013e328343d708

26 Andreone P, Catani L, Margini C, et al. Reinfusion of highly purified CD133+ bone marrow-derived stem/progenitor cells in patients with end-stage liver disease: A phase I clinical trial. Dig Liver Dis 2015;47(12):1059-1066. Doi: 10.1016/j.dld.2015.08.018

27 Tang KH, Ma S, Lee TK, et al. CD133(+) liver tumor-initiating cells promote tumor angiogenesis, growth, and self-renewal through neurotensin/interleukin-8/CXCL1 signaling. Hepatology 2012;55 (03):807-820. Doi: 10.1002/hep.24739

28 Association WMWorld Medical Association. World Medical Association Declaration of Helsinki: ethical principles for medical research involving human subjects. JAMA 2013;310(20):2191-2194. Doi: 10.1001/jama.2013.281053

29 Bradford MM. A rapid and sensitive method for the quantitation of microgram quantities of protein utilizing the principle of protein-dye binding. Anal Biochem 1976;72:248-254. Doi: 10.1016/0003-2697(76)90527-3

30 Aghajani M, Mansoori B, Mohammadi A, Asadzadeh Z, Baradaran B. New emerging roles of CD133 in cancer stem cell: Signaling pathway and miRNA regulation. J Cell Physiol 2019;234(12): 21642-21661. Doi: 10.1002/jcp.28824

31 Ko SBH, Mizuno N, Yatabe Y, et al. Corticosteroids correct aberrant CFTR localization in the duct and regenerate acinar cells in autoimmune pancreatitis. Gastroenterology 2010;138(05): 1988-1996. Doi: 10.1053/j.gastro.2010.01.001

32 Shidal C, Singh NP, Nagarkatti P, Nagarkatti M. MicroRNA-92 Expression in $\mathrm{CD}_{133^{+}}$Melanoma Stem Cells Regulates Immunosuppression in the Tumor Microenvironment via Integrin-Dependent Activation of TGF $\beta$. Cancer Res 2019;79(14):3622-3635. Doi: 10.1158/0008-5472.can-18-2659

$33 \mathrm{Hu}$ B, Li G, Ye Z, et al. Transcription factor networks in aged naïve CD4 T cells bias lineage differentiation. Aging Cell 2019;18(04): e12957. Doi: 10.1111/acel.12957

34 Xue G, Jin G, Fang J, Lu Y. IL-4 together with IL-1 $\beta$ induces antitumor Th9 cell differentiation in the absence of TGF- $\beta$ signaling. Nat Commun 2019;10(01):1376. Doi: 10.1038/s41467-01909401-9

35 Ilnicka A, Gocek E, Łopatecka J, Marcinkowska E. Regulation of FOXP3 expression in myeloid cells in response to all-trans-retinoic acid, interleukin 2 and transforming growth factor $\beta$. Dev Comp Immunol 2019;96:18-26. Doi: 10.1016/j.dci.2019.02.019

36 Zhang S. The role of transforming growth factor $\beta$ in T helper 17 differentiation. Immunology 2018;155(01):24-35. Doi: 10.1111/ imm. 12938

37 Smith KA, Pulsipher A, Gabrielsen DA, Alt JA. Biologics in Chronic Rhinosinusitis: An Update and Thoughts for Future Directions. Am J Rhinol Allergy 2018;32(05):412-423. Doi: $10.1177 / 1945892418787132$

38 Xie K. Interleukin-8 and human cancer biology. Cytokine Growth Factor Rev 2001;12(04):375-391. Doi: 10.1016/S1359-6101(01) 00016-8

39 Bachi ALL, Rios FJO, Vaisberg PHC, et al. Neuro-immuno-endocrine modulation in marathon runners. Neuroimmunomodulation 2015;22(03):196-202

40 Kim JA, Cho JH, Park I-H, Shin JM, Lee SA, Lee HM. Diesel Exhaust Particles Upregulate Interleukins IL-6 and IL-8 in Nasal Fibroblasts. PLoS One 2016;11(06):e0157058. Doi: 10.1371/journal. pone. 0157058

41 Barzegar Behrooz A, Syahir A, Ahmad S. CD133: beyond a cancer stem cell biomarker. J Drug Target 2019;27(03):257-269. Doi: 10.1080/1061186X.2018.1479756 